\title{
Um Panorama da Pesquisa Internacional sobre Mudança Conceitual
}

\section{A Landscape of the International Research on Conceptual Change}

\section{Alexsandro Pereira de Pereira ${ }^{\circledR}$ Brasil}

Apresentamos quatro distinções básicas para revisar a pesquisa internacional sobre mudança conceitual: (1) as abordagens clássica e reenquadrada à mudança conceitual; (2) as perspectivas da coerência e da fragmentação do conhecimento intuitivo; (3) as tendências frias e aquecidas na pesquisa em mudança conceitual; (4) as abordagens cognitiva e situativa à cognição humana. De acordo com essas distinções, a mudança conceitual não é uma substituição de uma concepção por outra, mas sim o uso de uma concepção adequada de acordo com o contexto. Além disso, as concepções são descritas não apenas em termos de estruturas do tipo teoria, mas também em termos de conhecimento em pedaços. Adicionalmente, a mudança conceitual não é vista como um processo puramente racional, mas sim como algo que envolve aspectos motivacionais e fatores contextuais de sala de aula. Finalmente, a mudança conceitual envolve não apenas a mente individual, mas também um conjunto de artefatos e sistemas simbólicos disponíveis em contextos socioculturais particulares.

Palavras-chave: mudança conceitual; controvérsias; revisão da literatura.

In this paper, we present four basic distinctions to review the modern research on conceptual change: (1) the classical and re-framed approaches to conceptual change; (2) the coherence and fragmentation perspectives of intuitive knowledge; (3) the cold and warming trends in conceptual change research; (4) the cognitive and situative approaches to human cognition. According to these distinctions, conceptual change is not a matter of replacing one conception with another, but of evoking an appropriate conception depending on the context. In this connection, conceptions are described not only in terms of theory-like structures, but also in terms of knowledge in pieces. In addition, conceptual change is not viewed as a purely rational process, but rather as a process involving motivation and classroom contextual factors. Finally, conceptual change involves not only individual minds, but also a set of artifacts and symbolic systems available in particular socio-cultural contexts.

Keyword: conceptual change; controversies, review of the Literature. 


\section{Introdução}

A pesquisa em mudança conceitual é bem difícil de revisar (diSessa, 2006). O problema da mudança conceitual é discutido na História e Filosofia da Ciência desde a década de 60, quando autores como Thomas Kuhn e Paul Feyerabend lançaram uma forte crítica sobre o positivismo lógico (Arabatzis \& Kindi, 2008). Este debate teve grande impacto em duas tradições de pesquisa relativamente independentes: a Educação em Ciências e a Psicologia do Desenvolvimento (Vosniadou, 1999). Na Educação em Ciências, a gênese da mudança conceitual pode ser encontrada no artigo seminal de George J. Posner e seus colaboradores (Posner, Strike, Hewson, \& Gertzog, 1982). $\mathrm{Na}$ Psicologia do Desenvolvimento, a mudança conceitual está ligada aos estudos de Susan Carey (1985) sobre o desenvolvimento cognitivo na infância. Nas últimas duas décadas, psicólogos da Educação têm expandido a abordagem da mudança conceitual para outros domínios além das Ciências da Natureza, incluindo a História (e.g., Limón, 2002), a Matemática (e.g., Vosniadou \& Verschaffel, 2004), o campo da Medicina e Saúde (Kaufman, Keselman \& Patel, 2008), entre outros. De fato, o termo mudança conceitual pode ser encontrado até na área das Ciências Políticas (e.g., Ball \& Pocock, 1988).

A pesquisa em mudança conceitual tem se tornado um movimento internacional, apoiado por associações, congressos, livros especializados (Guzzetti \& Hynd, 1997; Limón \& Mason, 2002; Schnotz, Vosniadou, \& Carretero, 1999; Sinatra \& Pintrich, 2003; Vosniadou, 2008c; Vosniadou, Baltas, \& Vamvakoussi, 2007), revisões da literatura (Driver, 1989; Duit \& Treagust, 2003; Özdemir \& Clark, 2007; Treagust \& Duit, 2008b, 2009; Tyson,Venville, Harrison, \& Treagust, 1997) e números especiais de periódicos acadêmicos (cronologicamente: Learning and Instruction, 4(1), 1994; Human Development, 37(4), 1994; European Journal of Psychology of Education, 7(2), 1997; The Journal of the Learning Science, 6(1), 1997; Enseñanza de las Ciencias, 17(1), 1999; Learning and Instruction, 11(4/5), 2001; Learning and Instruction, 14(5), 2004; Educational Psychologist, 42(1), 2007; Cultural Studies of Science Education, 3(2), 2008). A convergência de várias disciplinas no esforço de entender a mudança conceitual levou ao surgimento de um subcampo por direito próprio. De fato, nós temos nos dias de hoje um novo programa de pesquisa em mudança conceitual.

Isso não quer dizer que todos os que atuam neste novo programa falam em uma única voz. De acordo com Andrea diSessa, "o envolvimento de múltiplas disciplinas tem produzido uma pletora de orientações e teorias" (diSessa, 2006, p. 266, nossa tradução). Em consequência disso, mudança conceitual tem se tornado um termo vago. Nas palavras de Eduardo F. Mortimer, "assim como 'construtivismo,' 'mudança conceitual' se tornou um rótulo que cobre um grande número de visões diferentes e às vezes inconsistentes" (Mortimer, 1995, p. 267, nossa tradução). De maneira similar, Michelene Chi e Rod Roscoe apontaram que "embora a mudança conceitual tenha sido discutida por várias décadas dentro de diferentes contextos de pesquisa, a literatura, no entanto, apresenta uma imagem até certo ponto borrada do que são exatamente as concepções alternativas, o que constitui a mudança conceitual e por que a mudança conceitual é difícil" (Chi \& 
Roscoe, 2002, p. 4, nossa tradução).

No intuito de delinear o panorama conceitual dentro do qual a pesquisa em mudança conceitual tem sido estruturada, apresentamos quatro distinções básicas: as abordagens clássica e reenquadrada, as perspectivas da coerência e da fragmentação, as tendências frias e aquecidas e as abordagens cognitiva e situativa. É importante salientar que outras revisões da literatura já mostraram as múltiplas perspectivas da mudança conceitual (ontológica, epistemológica, sócio/afetiva), no intuito de integrá-las em um quadro teórico multidimensional (Duit \& Treagust, 2003; Tyson et al., 1997). No entanto, acreditamos que algumas dessas perspectivas estão em oposição fundamental e, portanto, são mais bem entendidas como controvérsias do que como dimensões complementares. Em vez de assumir que elas restringem a investigação, o ponto de partida da presente revisão é a tese de que essas controvérsias são a força-motora que impulsiona o desenvolvimento das diferentes perspectivas sobre a mudança conceitual. Assim, em vez de buscar pontos de consenso, nossa missão será identificar onde essas perspectivas divergem.

As distinções aqui apresentadas são fundamentais se quisermos evitar falsos desacordos em debates acadêmicos. Um exemplo disso pode ser encontrado em um artigo de Wolf-Michael Roth e seus colaboradores (Roth, Lee, \& Hwang, 2008). De acordo com esses autores "a inteligibilidade das 'concepções alternativas' mina qualquer tentativa de 'erradicá-las' completamente por meio da instrução" (Roth, Lee, \& Hwang, 2008, p. 234, nossa tradução). Essa alegação, embora correta, é mal direcionada, tornando o trabalho de autores como Peter Hewson (2008) e Stella Vosniadou (2008a) fácil demais. Em resposta ao trabalho de Roth et al. (2008), Hewson escreveu que "a imagem da mudança conceitual pintada por Roth e seus colegas tem características que são caricaturas grotescas que não tem lugar em artigos acadêmicos" (Hewson, 2008, p. 264, nossa tradução). Vosniadou, por sua vez, concordou com as críticas de Roth et al. e alegou que "quando os autores falam sobre 'mudança conceitual', eles parecem se referir ao que é conhecido como a 'abordagem clássica’ à mudança conceitual, conforme apresentada por Posner e seus colegas” (Vosniadou, 2008a, p. 278, nossa tradução).

\section{Metodologia}

Artigos de revisões da literatura costumam envolver um intenso trabalho de consulta aos principais periódicos da área. Dependendo do tema investigado (e dos propósitos de quem investiga), materiais como teses e dissertações, documentos oficiais, capítulos de livros e até obras completas são incluídos no trabalho de revisão. A definição do corpus da pesquisa normalmente é feita a partir da busca, em um banco de dados, por palavras-chave relacionadas ao tema de interesse. O investigador deve se certificar de que a busca cobre o período de tempo desejável, para que nenhum trabalho importante fique de fora da revisão. Após a definição do corpus, começa a etapa de análise do material levantado. Os trabalhos analisados são então categorizados segundo algum critério de classificação, definido a priori ou durante o próprio processo de revisão. 
No presente artigo, adotamos uma abordagem mais exploratória, baseada na leitura de artigos seminais e de revisões anteriores da literatura. Essa amostra inicial de leituras nos levou a outras referências relevantes (incluindo capítulos de livros) que, por sua vez, nos levaram a outras referências, e assim sucessivamente até constituir o corpus de nossa pesquisa. Em vez de criar novas categorias para classificar os estudos sobre mudança conceitual, procuramos identificar as principais controvérsias existentes neste campo de estudo. Essa metodologia é inspirada em um trabalho de revisão sobre memória coletiva, desenvolvido por Wertsch e Roediger (2008). Uma alternativa metodológica seria descrever todos os artigos que reportam estudos empíricos sobre mudança conceitual nos principais periódicos da área nos últimos, digamos, dez anos. Entretanto, acreditamos que isso produziria uma visão menos clara do panorama conceitual que estrutura as pesquisas em mudança conceitual. Ao adotar a metodologia aqui descrita, estamos conscientes de que nossa revisão não esgota o universo de perspectivas teóricas que continuam a surgir na literatura sobre mudança conceitual.

\section{Os diversos significados da mudança conceitual}

Diversos autores têm apontado para a falta de precisão que ainda existe no vocabulário usado pelos pesquisadores da mudança conceitual para definir a natureza daquilo que as estratégias de ensino supostamente deveriam mudar (e.g., Caravita, 2001; Limón; 2001; Sfard, 2007). De acordo com diSessa (2006), o termo mudança conceitual incorpora uma primeira aproximação da principal dificuldade dos alunos, qual seja, a de construir novas ideias a partir do conhecimento atual - por isso a ênfase na mudança e não na simples aquisição. Apesar disso, a palavra mudança tem sido usada na literatura de três maneiras distintas (Hewson, 1992): (1) mudança como transformação - como a história do sapo que vira príncipe; (2) mudança como troca - como a mudança de prefeito em uma cidade; (3) mudança como extensão - como uma pequena cabana de quatro quartos que teve um banheiro e uma cozinha anexada a ela.

O qualificador conceitual, por sua vez, parece ainda mais ambíguo. A primeira vista, o termo sugere que a mudança conceitual lida com a mudança de conceitos. No entanto, se lembrarmos de que o estudo da mudança conceitual se originou no contexto de outro programa de pesquisa, a saber, o movimento das concepções alternativas, então fica claro que a mudança conceitual deve ter como foco a mudança de concepções. No artigo original de Posner et al. (1982), os autores usaram os termos concepção e conceito de modo indiferenciado, apesar de reconhecerem que eles se referem a diferentes níveis de conceitualização. Já na pesquisa de Carey (1985), a autora deu ênfase aos conceitos, apesar de ter sido criticada por não levar em conta a gama de pressupostos subjacentes àquilo que constitui um conceito (diSessa \& Sherin, 1998). No âmbito da Filosofia da Ciência, Stephen Toulmin argumentou que "o termo conceito é um dos que todo mundo usa e ninguém explica - muito menos define” (Toulmin, 1972, p. 8, nossa tradução).

Em um número especial da Learning and Instruction, Richard T. White argumentou que o progresso da pesquisa educacional requer uma maior precisão nos 
termos usados "para que não fiquemos perdidos no jargão, termos significativos apenas para seus inventores, com teorias divergindo ao ponto onde não há comunicação" (White, 1994, p. 117, nossa tradução). Assim como outros autores, White enfatizou que o termo conceitual tem sido relacionado a outras duas palavras, conceito e concepção. Conceito, por sua vez, é usado de duas maneiras distintas. A primeira maneira diz respeito à classificação. Ter um conceito, nessa perspectiva, significa ser capaz de classificar, de forma precisa, um objeto ou evento como membro de uma classe. Alguns autores como Carey (1985) e Chi e Roscoe (2002) parecem usar esse significado. A segunda maneira está relacionada com todo o conhecimento que uma pessoa tem e associa com o nome do conceito. Segundo essa definição, um conceito muda sempre que aprendemos algo novo sobre ele. Esse tipo de mudança é relativamente fácil de alcançar e raramente envolve a reconstrução do restante do conhecimento acerca do conceito, sem falar de outros conceitos. Essas mudanças menores têm sido referidas na literatura sob o título de "acreção" (Vosniadou, 1994).

O conhecimento novo pode, no entanto, ter um efeito de longo alcance no significado total que é atribuído a um conceito. Ele pode envolver a revisão de crenças anteriores e afetar a ação do sujeito. Essas mudanças maiores tipicamente envolvem explicações detalhadas de fenômenos e representam aquilo que White (1994) chamou de "mudança concepcional". Nesse sentido, as concepções são vistas como "sistemas de explicações". Essa distinção entre concepção e conceito, formulada por White, captura alguns dos (mas não todos os) vários sentidos usados para caracterizar a mudança conceitual.

\section{Quatro distinções básicas para revisar a mudança conceitual}

Dado o estado fragmentado dos debates acadêmicos sobre mudança conceitual, a busca por uma definição única e amplamente aceita torna-se uma tarefa contraproducente. Essa falta de acordo diz respeito não apenas a termos e definições básicas, mas também aos métodos empregados na pesquisa. Nas palavras de diSessa e colaboradores:

Além da intratabilidade de diferenças teóricas profundas, o estudo da mudança conceitual tem sido limitado pelo fato de que a pesquisa tem sido um tanto espalhada através de um amplo conjunto de domínios (e.g., a forma da Terra, os efeitos da força, o significado de "vivo", a distinção entre calor e temperatura) e através de uma ampla gama de idades, desde a pré-escola até estudantes universitários. Além disso, as metodologias de vários pesquisadores têm envolvido coleta de dados tão diversa quanto entrevistas clínicas, atuações em montagens físicas ou implementadas com computadores e respostas a questões escritas. A análise de dados varia desde "codificar e contar" até a construção qualitativa de teorias. Por falta de uma base comum, é possível que diferentes resultados sejam mais o resultado de se fazer diferentes perguntas, de diferentes maneiras, sobre diferentes assuntos. (diSessa, Gillespie, \& Esterly, 2004, p. 844, nossa tradução)

Além de mudança conceitual, outras noções relacionadas como "crescimento conceitual” (Greeno \& Sande, 2007), “prática conceitual” (Krange, 2007), “apreciação 
conceitual” (Linder, 1993), "perfil conceitual” (Mortimer, 1995), “mudança representacional" (Pozo, Gómez, \& Sanz, 1999), "revoluções conceituais" (Thagard, 1992), "mudança concepcional" (White, 1994), "mudança discursiva” (Wickman \& Östman, 2002) - e a lista continua - têm surgido na literatura, o que reflete um amplo espectro de perspectivas, assim como a falta de uma base comum. De fato, o estado da arte da pesquisa em mudança conceitual pode ser descrito como "múltiplas perspectivas que combinam muito senso comum e ideias teóricas de forma caleidoscópica" (diSessa, 2006, p. 266, nossa tradução).

Assim, em vez de procurar por uma definição única e precisa, talvez seja mais produtivo apresentar um conjunto de distinções básicas que caracterizam a produção científica sobre a mudança conceitual. Apesar de tais distinções serem facilmente encontradas na literatura (e.g., diSessa et al., 2004; Mason, 2007; Sinatra, 2005; Vosniadou, 2007b), esta é a primeira vez que elas são apresentadas juntas, fornecendo um panorama desse campo de estudo. A primeira distinção a ser apresentada, entre as abordagens clássica e reenquadrada, fornece o ponto de partida para uma série de questões que serão discutidas no âmbito das demais distinções: entre as perspectivas da coerência e da fragmentação, entre as tendências frias e aquecidas e entre as abordagens cognitiva e situativa.

\section{As abordagens clássica e reenquadrada}

A primeira distinção básica a ser feita, a fim de se revisar a pesquisa em mudança conceitual, é entre as abordagens clássica e reenquadrada (Vosniadou, 2007b). A abordagem clássica é uma visão de aprendizagem proposta por Posner et al. (1982) no início dos anos 80 . Nessa década, havia uma extensiva literatura indicando que as crianças vão às aulas de ciência com concepções pré-existentes que costumam diferir substancialmente das ideias a serem ensinadas e que são, com frequência, resistentes à mudança (Driver, 1989). Com o intuito de expandir o pressuposto construtivista de que a aprendizagem é o resultado da interação entre aquilo que é ensinado aos estudantes e suas ideias iniciais, Posner e seus colegas formularam uma teoria para explicar e descrever "o processo pelo qual os conceitos centrais e organizadores das pessoas mudam de um conjunto de conceitos para outro conjunto, incompatível com o primeiro" (Posner et al., 1982, p. 211, nossa tradução). Posner et al. (1982) assumiram que a principal fonte de hipóteses relacionada à mudança conceitual é a Filosofia da Ciência. De acordo com essa visão, existe um padrão análogo entre a aprendizagem individual e a mudança em disciplinas científicas. Partindo da noção de "ciência normal" de Thomas Kuhn (1970) e das ideias de Imre Lakatos (1970) sobre os "programas de pesquisa", os autores vislumbraram uma primeira fase da mudança conceitual, que envolve o uso de conceitos pré-existentes para lidar com novos fenômenos. Eles chamaram essa primeira fase de assimilação. A segunda fase da mudança conceitual ocorre quando as ideias iniciais do estudante são inadequadas para permiti-los compreender um novo fenômeno de forma bem sucedida. Neste caso, o estudante precisa substituir ou reorganizar seus conceitos 
centrais. Essa forma mais radical de mudança conceitual, que é análoga ao conceito de revolução científica de Kuhn ou a noção de mudança de programas de pesquisa de Lakatos, os autores denominaram acomodação. Apesar de serem termos piagetianos, as noções de assimilação e acomodação não implicam qualquer compromisso com as teorias de Piaget, conforme os autores indicaram em seu artigo original.

Existem duas componentes centrais nesse modelo de mudança conceitual. A primeira delas refere-se às condições que precisam ser satisfeitas antes de uma acomodação acontecer. De acordo com essa visão: (1) precisa haver insatisfação com as concepções pré-existentes - é improvável que os alunos façam grandes mudanças em seus conceitos até perceberem que uma mudança menos radical não irá funcionar; (2) a nova concepção precisa ser inteligível - o primeiro obstáculo que uma nova concepção precisa encarar para ganhar aceitação é parecer fazer sentido; (3) a nova concepção precisa parecer plausivel - ela precisa parecer verdadeira e ter a capacidade de resolver problemas gerados por suas antecessoras (caso contrário, não parecerá uma escolha plausível); (4) a nova concepção precisa ser fértil - ela precisa ter o potencial para ser expandida a novas áreas de investigação.

A segunda componente central do modelo de mudança conceitual é a noção de ecologia conceitual. Esse termo, que foi cunhado originalmente por Toulmin (1972), se refere à bagagem de conceitos centrais do estudante, através da qual a aprendizagem é organizada. São esses conceitos que permitem que o estudante faça perguntas sobre um novo fenômeno, saiba o que contaria como uma resposta adequada à pergunta ou distinga características do fenômeno que são relevantes daquelas que não o são. $O$ conceito de ecologia conceitual compartilha várias características com a noção kuhniana de paradigma ou com aquilo que Lakatos chamou de núcleo duro de uma teoria. Ele consiste de muitos tipos de conhecimento, tais como anomalias, analogias e metáforas, compromissos epistemológicos, crenças metafísicas e conhecimento em outras áreas. Em suma, a ecologia conceitual é o que governa a mudança conceitual, influenciando a seleção de um novo conceito central.

Hewson (1981) expandiu a teoria original de Posner et al. (1982) para incluir outros aspectos da mudança conceitual. Em sua própria versão do modelo, ele usou os termos captura conceitual e mudança conceitual para se referir aos processos de assimilação e acomodação, respectivamente. Ele introduziu a noção de status de um conceito no intuito de avaliar em que medida um novo conceito alcança as condições de inteligibilidade, plausibilidade e fertilidade. De acordo com essa perspectiva, quanto mais condições um conceito alcança, maior é seu status. Para avaliar as possibilidades do que pode ocorrer quando um estudante é confrontado com um novo conceito, é preciso considerar o status de ambas as concepções, a velha e a nova, assim como se a nova concepção é conciliável com as demais concepções pré-existentes. Assim, o papel do professor de ciências, nessa visão, consiste em reduzir o status das concepções alternativas dos estudantes para permitir que a mudança conceitual ocorra.

Esse modelo de mudança conceitual se tornou o principal paradigma que orientou 
as pesquisas em Educação em Ciências por vários anos (Vosniadou, 2007b). De fato, mudança conceitual se tornou um sinônimo de aprendizagem (Niedderer, Goldberg, \& Duit, 1991). Nos anos 90, no entanto, essa “abordagem clássica” à mudança conceitual, como passou a ser chamada na literatura (e.g., Duit \& Treagust, 2003), se tornou o foco de intensa crítica. Uma característica em particular que foi bastante criticada é a alegação de que os estudantes deveriam abandonar suas ideias iniciais em favor das novas ideias científicas - algo que poderia ser chamado de pressuposto da substituição. Diferentemente de outras controvérsias existentes nesse campo de estudo, essa é uma que já foi resolvida tendo em vista que nenhum pesquisador da atualidade tem defendido esse pressuposto (pelo menos não explicitamente).

O principal desafio à mudança conceitual foi formulado por Cedric J. Linder (1993). De acordo com o autor, a descrição de aprendizagem da mudança conceitual deveria ser estendida para incluir a adequação conceitual baseado em um contexto. Com base na perspectiva fenomenográfica, apresentada por pesquisadores da Universidade de Gothenburg, na Suécia, o autor alegou que as concepções são mais bem entendidas como categorizações de categorias de descrições. De acordo com essa visão, a mudança conceitual é atingida na medida em que mudamos a relação das pessoas com o contexto, $o$ que envolve a habilidade de reconhecer um contexto e, em termos desse reconhecimento, evocar a concepção adequada. Assim, o objetivo central do ensino de ciências, nessa perspectiva, seria o de fazer com que os alunos entendam diferentes conceitualizações de um conceito. Essa mesma linha de raciocínio está por de trás do influente artigo de Solomon (1983) e se alinha com os trabalhos de Caravita e Halldén (1994), Cobern (1996), Mortimer (1995), Pozo et al. (1999) e Spada (1994).

De modo geral, existem várias características da mudança conceitual que se tornaram alvo de críticas. Resumidamente, na base da abordagem clássica o estudante é visto como um cientista, a aprendizagem como um processo radical de substituição de teorias, a mudança conceitual como uma troca do tipo Gestalt, que ocorre em um curto período de tempo, e o conflito cognitivo como a principal estratégia de ensino para a mudança conceitual (Vosniadou, 2007b). Todos esses princípios da mudança conceitual foram seriamente questionados e a busca por novos quadros teóricos tem levado ao que se conhece hoje como a abordagem reenquadrada à mudança conceitual.

O termo reenquadrar (re-framing) foi originalmente utilizado por Caravita e Halldén (1994) para sugerir uma visão alternativa ao da mudança conceitual. Os autores levantaram algumas críticas contra o paralelismo que havia sido traçado entre a aprendizagem de ciências na escola e o desenvolvimento cognitivo na infância, ou entre o primeiro e o desenvolvimento histórico das teorias científicas. Em vez de representar a aprendizagem em termos de substituição de ideias, eles alegaram que a mudança conceitual envolve um conjunto de maneiras de pensar sobre um domínio conceitual, as quais são suscitadas em contextos específicos de ação e discurso. A partir de um estudo empírico envolvendo estudantes da quarta série, atuando em quatro diferentes atividades instrucionais envolvendo o conceito biológico de organismo, os autores concluíram que 
tais atividades levaram à construção de uma visão mais sistêmica do corpo humano e animal. Na perspectiva dos autores, o entendimento científico aumenta no decorrer de um longo período de tempo e requer vários contextos de aplicação de várias estratégias de aprendizagem.

Mais recentemente, reenquadrar se tornou uma expressão que denota uma visão mais contemporânea de mudança conceitual. Segundo Vosniadou, a abordagem reenquadrada é "uma abordagem construtivista, de domínio específico, que evita muitas das críticas a tentativas anteriores de explicar o processo de mudança conceitual na aprendizagem e no desenvolvimento" (Vosniadou, 2007a, p. 11, nossa tradução). Na sua própria versão da mudança conceitual, as concepções alternativas são modelos mentais sintéticos criados durante a instrução formal, quando elementos das teorias científicas são assimilados ao quadro explicativo inicial da criança. De acordo com essa visão, mudança conceitual é um processo lento e gradual, em que elementos desse quadro explicativo inicial vão sendo reestruturados de modo a torna-lo consistente com a visão científica atualmente aceita.

Uma alternativa à abordagem teórica de Vosniadou pode ser encontrada nos trabalhos de Michelene Chi (Chi, 1992; Chi \& Roscoe, 2002; Chi, Slotta, \& Leeuw, 1994). Em sua abordagem ontológica, as concepções alternativas são vistas como categorizações equivocadas de conceitos (miscategorizations), o que acontece sempre que uma criança associa um conceito a uma "categoria ontológica" errada (Chi, 1992). Conceitos como calor e força, por exemplo, são, com frequência, descritos como substâncias quando, na verdade, eles são cientificamente categorizados como processos. Na Ciência Cognitiva, substâncias e processos são categorias que pertencem a diferentes "árvores ontológicas" (Chi et al., 1994). Nessa perspectiva, mudança conceitual é meramente um processo de reclassificação ou, melhor dizendo, a troca de um conceito mal categorizado de uma categoria ontológica para outra. Tal processo não é inerentemente difícil, mas pode ser desafiador se o aluno não tiver consciência de quando uma troca ontológica é necessária ou se ele não tiver outra categoria ontológica para reclassificar seus conceitos.

Em síntese, a abordagem reenquadrada é uma tentativa dos pesquisadores da mudança conceitual de superar as dificuldades do modelo original de Posner et al. (1982). Esse movimento representa uma mudança profunda no estudo da mudança conceitual. De fato, alguns pesquisadores têm alegado que a própria pesquisa em mudança conceitual tem sofrido uma mudança conceitual radical (Vosniadou, 2008b). Assim, qualquer tentativa de criticar a abordagem da mudança conceitual que não leve em consideração a distinção entre as abordagens clássica e reenquadrada corre o sério risco de ser mal direcionada.

\section{As perspectivas da coerência e da fragmentação}

Outra distinção básica na pesquisa em mudança conceitual é entre as perspectivas da coerência e da fragmentação do conhecimento intuitivo. Essa distinção representa uma das mais importantes controvérsias nesse campo de estudo, que tem estado no 
centro de debates acalorados. Uma característica influente na pesquisa em mudança conceitual é a analogia com a História e Filosofia da Ciência. Às vezes, essa analogia se refere ao conteúdo científico, fazendo um paralelo entre as ideias ingênuas dos estudantes e teorias científicas medievais (e.g., Clement, 1982; McCloskey, 1983; Viennot, 1979). Outras vezes, esta analogia diz respeito ao mecanismo de mudança, estabelecendo um link entre o desenvolvimento histórico de teorias científicas, conforme discutido por filósofos e historiadores da Ciência, e mudanças ontogenéticas na aprendizagem dos indivíduos (e.g., Carey, 1985; Posner et al., 1982). E conforme apontou diSessa (2006), intimamente relacionado com essa analogia com a História e Filosofia da Ciência está a perspectiva da coerência - algo que ele chamou de "teoria da teoria" (the theory theory).

A perspectiva da coerência é uma visão, na Ciência Cognitiva, que representa o conhecimento intuitivo (e.g., a Física ingênua) como sendo organizado em "estruturas do tipo teoria" (Vosniadou, 2007b). Na perspectiva da coerência, as crianças têm teorias no mesmo sentido em que um cientista as tem. Alguns autores são mais cautelosos a esse respeito e apontam diferenças entre ideias ingênuas e teorias científicas, tais como consciência meta-cognitiva, limites na sistematicidade e amplitude de aplicação (e.g., Vosniadou, 2002). Mesmo assim, eles com frequência assumem que as crianças usam suas teorias ingênuas para formular explicações e fazer previsões de fenômenos do cotidiano. Presume-se que tais explicações e previsões são consistentes em diferentes contextos. De acordo com essa visão, o processo de aquisição de conhecimento é um processo revolucionário, similar a mudanças de paradigma na História da Ciência.

Uma das principais proponentes da perspectiva da coerência é Carey (1985). A autora é pioneira no uso de analogias com a História e Filosofia da Ciência e em estudos do desenvolvimento cognitivo. Carey alega que teorias de domínio geral da inteligência não podem explicar as mudanças que ocorrem na biologia intuitiva das crianças. Em vez de descrever o desenvolvimento cognitivo em termos de mudanças na estrutura de pensamento ocorridas pelo crescimento das capacidades lógicas da criança, conforme a tradição piagetiana, ela argumentou que as crianças desenvolvem teorias intuitivas conforme elas aumentam seu conhecimento em um domínio específico. $\mathrm{Na}$ teoria de Carey, há dois tipos de mudança conceitual: (1) a reestruturação fraca, que envolve novas relações entre conceitos, motivando a criação de um novo esquema ou a mudança de crenças; (2) a reestruturação forte, que envolve processos mais radicais tais como a diferenciação (a separação de um conceito em dois novos conceitos) e a coalescência (a união de dois conceitos distintos). Apesar de ela reconhecer que a exatidão da perspectiva da coerência é uma questão empírica, ela insiste que "precisamos apelar para teorias intuitivas para declarar restrições na indução, para explicar compromissos ontológicos e noções causais, para analisar a mudança conceitual e assim por diante" (Carey, 1986, p. 1129, nossa tradução).

Outra influente defensora da perspectiva da coerência é Vosniadou (1994; 2002; 2007b). A autora é considerada a mãe da pesquisa contemporânea em mudança conceitual. Em sua abordagem à mudança conceitual, as crianças começam o processo de 
aquisição do conhecimento organizando a multiplicidade de experiências sensoriais, sob a influência da cultura cotidiana, em um limitado, porém coerente quadro explicativo, o qual ela chamou de "teoria quadro" (framework theory). Teorias quadro são sistemas complexos constituídos de informação perceptual, crenças, pressupostos ontológicos e epistemológicos e modelos mentais. Segundo essa teoria, as crenças são formadas a partir de observações superficiais da realidade física, enquanto que os pressupostos constituem construtos teóricos mais profundos que são mais difíceis de mudar (Vosniadou, 1999). Modelos mentais, por sua vez, são representações dinâmicas e generativas que podem ser manipuladas mentalmente para fornecer explicações causais e fazer previsões de fenômenos físicos (Vosniadou, 1994).

Assim como as teorias quadro facilitam o processo de aquisição do conhecimento, elas também podem impedir o aprendizado subsequente, em particular no caso de conceitos científicos. Isso porque as explicações científicas atualmente aceitas dos fenômenos são, com frequência, bastante distintas daquelas que as crianças constroem com base na experiência diária, antes mesmo de serem expostas à instrução formal. A esse respeito, Vosniadou e Brewer (1992) relataram que crianças de idade escolar concebem a Terra como um objeto físico (ao invés de astronômico), com a forma de um retângulo ou um disco plano. Essa concepção inicial influencia na maneira como elas interpretam a informação sobre a forma esférica da Terra. Algumas crianças acreditam que a Terra é esférica, mas possui um dos polos achatados (onde as pessoas vivem). Outras acreditam que a Terra é uma esfera oca, com as pessoas vivendo em um terreno plano no seu interior. Essas concepções alternativas são tentativas, por parte das crianças, de reconciliar a informação que elas recebem da cultura (normalmente através da instrução formal) de que a Terra é uma esfera com seus pressupostos e crenças de que o chão é plano, o espaço é organizado em termos das direções para cima e para baixo, objetos não sustentados caem para baixo, etc. (Vosniadou, 1999).

Em suma, na perspectiva da teoria quadro, as concepções alternativas são modelos sintéticos que as crianças geram durante a instrução formal. Esses modelos sintéticos são desenvolvidos porque as crianças não tem conhecimento explícito de suas próprias crenças e, portanto, não entendem as contradições existentes entre suas teorias ingênuas e as explicações científicas as quais elas são expostas, nem as distorções da visão científicas que elas geram (Vosniadou, 2007b). Assim, a mudança conceitual é vista como um processo lento e gradual, no qual aspectos da informação científica são adicionados à teoria quadro, destruindo sua coerência até que a mesma seja reestruturada de modo a se tornar consistente com as teorias científicas atualmente aceitas. Esse processo requer não apenas a reestruturação das teorias ingênuas dos estudantes, mas também uma consciência meta-conceitual e intencionalidade.

No outro lado da controvérsia, um grupo complementar de pesquisadores tem alegado que as ideias ingênuas das crianças são muitas, diversificadas e a-teóricas em qualquer sentido mais profundo (diSessa et al., 2004). Tal posição tem crescido gradualmente em influência e representa o lado fragmentado do debate. De acordo com 
essa visão, as concepções prévias dos estudantes são representadas com mais precisão como uma coleção de múltiplos elementos quase independentes, que são disparados em determinados contextos. A partir desse ponto de vista, o processo de aquisição de conhecimento envolve o crescimento gradual de sistematicidade e coerência entre esses fragmentos de conhecimento. Assim, a mudança conceitual é vista como um processo evolucionário que envolve revisão, refinamento e reorganização do conhecimento inicial, na tentativa de se conectar de forma mais produtiva a um quadro conceitual mais normativo.

Um dos primeiros autores a defender a perspectiva da fragmentação do conhecimento foi Jim Minstrell (1982). Ele encarou as ideias ingênuas dos estudantes como recursos, em vez de obstáculos, para a mudança conceitual em Física. $\mathrm{Na}$ perspectiva desse autor, as ideias ingênuas são "linhas que, em vez de rejeitar, precisam se entrelaçar em um diferente, mais forte e mais normativo tecido conceitual" (diSessa, 2006, p. 273, nossa tradução). Anos mais tarde, Hunt e Minstrell (1994) usaram a noção de "facetas" para denotar ideias elementares e pedagogicamente relevantes que os estudantes levam para a sala de aula (e.g., coisas mais pesadas caem mais rápido). Eles rastrearam centenas de facetas em muitos tópicos no ensino de Física elementar, sendo que nenhuma teoria ingênua coerente foi encontrada neste estudo.

Outro partidário da perspectiva da fragmentação é Douglas B. Clark (2003). Ele realizou um estudo longitudinal de estudantes aprendendo elementos de calor e temperatura ao rastrear declarações do tipo facetas em entrevistas envolvendo resolução de problemas e explicações. As conclusões do autor se colocam firmemente no lado fragmentado do debate. De acordo com o autor, as facetas aumentavam e diminuíam no raciocínio dos alunos, mostravam conexões provisórias com outros elementos, os quais aumentavam apenas gradualmente e de maneira equivocada (diSessa et al., 2004). Esses resultados vão de encontro às afirmações anteriores de Wisner e Carey (1983) sobre o desenvolvimento do conhecimento de calor e temperatura.

O principal proponente da perspectiva da fragmentação é diSessa $(1988,1993$, 2002). O autor formulou uma abordagem teórica conhecida como "conhecimento em pedaços" (diSessa, 1988). De acordo com essa abordagem, o conhecimento intuitivo consiste de centenas ou milhares de esquemas autoexplicativos, os quais ele chamou de primitivos fenomenológicos, ou simplesmente p-prims (abreviação para phenomenological primitives). Os p-prims são abstraídos de situações comuns e são aproximadamente da escala de tamanho das facetas de Hunt e Minstrell (1994). Eles são ditos primitivos no sentido de que fornecem às pessoas a noção de quais eventos são naturais, quais são surpreendentes e por que. Eles são fenomenológicos no sentido de que costumam ser relativamente aparentes às pessoas em contextos do mundo real (e.g., a afirmação de que mais esforço gera mais resultado ${ }^{1}$ ). Outros exemplos de p-prims são as noções de força com um movedor, morrendo aos poucos, balanço dinâmico e retorno ao equilíbrio (ver diSessa, 1993).

1 Essa afirmação é um p-prims básico chamado p-prims de Ohm. Ele possui uma parte complementar que afirma que mais resistência gera menos resultado. 
Em suma, p-prims são vistos como sendo muitos, pouco organizados e às vezes altamente dependentes de contexto, de modo que o termo teoria torna-se bastante inapropriado. Os partidários da perspectiva da fragmentação tendem a se basear menos em termos da Filosofia e História da Ciência tais como conceitos e teorias. Seguindo um amplo espectro que vai desde o nível mais baixo até o nível mais alto, a abordagem teórica de diSessa inclui uma série de construtos, cada qual com sua própria definição: p-prims, fatos nominais, narrativas, modelos mentais e classes de coordenação. As "classes de coordenação" (diSessa \& Sherin, 1998) são modelos explícitos de certos tipos de conceitos. São sistemas complexos que incluem muitas partes coordenadas, incluindo p-prims. Assim, os p-prims são vistos como aninhados em classes de coordenação que, por sua vez, juntamente com modelos mentais e outras entidades cognitivas, formam a ecologia conceitual dos estudantes (diSessa, 2002).

Özdemir e Clark (2007) apontaram alguns pontos de consenso e justaposição entre as perspectivas da coerência e da fragmentação. Ambas as perspectivas assumem que os estudantes adquirem conhecimento a partir de experiências do cotidiano e que esse conhecimento influencia a aprendizagem formal. Elas também concordam que muito do conhecimento ingênuo é altamente resistente e que a reestruturação do conhecimento é um processo que consome tempo. Apesar desses pontos de consenso, a perspectiva da fragmentação assume que o conhecimento intuitivo consiste de múltiplos elementos quase independentes em vários estágios de desenvolvimento e sofisticação. Os novatos em um domínio particular conectam e ativam espontaneamente esses fragmentos de conhecimento de acordo com a relevância da situação. Durante a reestruturação do conhecimento, esses elementos e suas interações são revisados e refinados através de adição, eliminação e reorganização para fortalecer a rede. A partir dessa perspectiva, a mudança conceitual é um processo evolutivo fragmentado em vez de um processo amplo de substituição de teorias.

\section{As tendências frias e aquecidas}

Uma terceira distinção básica a ser feita na pesquisa em mudança conceitual é entre as tendências frias e aquecidas. A tendência fria se refere aos modelos excessivamente racionais de mudança conceitual, que são motivados principalmente pela metáfora do estudante como um cientista. Uma característica marcante da mudança conceitual que está intimamente ligada à perspectiva da coerência e à analogia mais ampla com História e Filosofia da Ciência é a visão racional de aprendizagem. De acordo com essa visão, os estudantes, assim como os cientistas, mantém suas ideias atuais, a menos que haja boas razões para abandoná-las. O modelo racional de mudança conceitual mais influente é provavelmente a teoria de Posner et al. (1982). Em seu artigo original, os autores apresentaram uma visão de aprendizagem na qual esse processo é análogo ao processo de investigação.

Nosso compromisso central neste estudo é o de que a aprendizagem é uma atividade racional. Quer dizer, a aprendizagem é fundamentalmente vir a compreender e a aceitar 
ideias porque elas são vistas como inteligíveis e racionais. A aprendizagem é, assim, um tipo de investigação. Os estudantes devem fazer julgamentos com base nas evidências disponíveis. (Posner et al., 1982, p. 212, nossa tradução)

É interessante notar que os autores reconhecem a influência de fatores motivacionais e afetivos no processo de aprendizagem. Entretanto, tais fatores são reduzidos a variáveis de segunda ordem, conforme podemos verificar no seguinte depoimento.

Isso, claro, não implica que variáveis motivacionais e afetivas não são importantes para o processo de aprendizagem. A alegação de que a aprendizagem é uma atividade racional tem a intenção de chamar a atenção para aquilo que a aprendizagem é, e não para aquilo de que a aprendizagem depende (Posner et al., 1982, p. 212, nossa tradução).

E os autores vão mais adiante ao afirmar que:

A aprendizagem diz respeito a ideias, sua estrutura e as evidências para suportá-las. Não é simplesmente a aquisição de um conjunto de respostas corretas, um repertório verbal ou um conjunto de comportamentos. Acreditamos que isso implica que a aprendizagem, assim como a investigação, é mais bem vista como um processo de mudança conceitual. A questão básica diz respeito a como as concepções dos estudantes mudam sob o impacto de novas ideias e novas evidências. (Posner et al., 1982, p. 212, nossa tradução)

Dez anos mais tarde, Strike e Posner (1992) deram um passo à trás em seu modelo racional, admitindo a necessidade de se incluir fatores motivacionais e afetivos em sua teoria original. Conforme Sinatra (2005) tem apontado, é irônico que tenha levado dez anos para os autores reconhecerem a necessidade de incluir tais fatores, visto que a própria noção de insatisfação - a primeira condição a ser atingida para a ocorrência da mudança conceitual - fornece claramente uma razão afetiva para o estudante mudar seu conhecimento existente.

Uma ampla gama de fatores precisa ser levada em conta ao tentar descrever a ecologia conceitual de um aprendiz. Motivos e objetivos e suas fontes sociais e institucionais precisam ser consideradas. A ideia de uma ecologia conceitual assim precisa ser mais abrangente do que os fatores epistemológicos sugeridos pela História e Filosofia da Ciência. (Strike \& Posner, 1992, p. 162, nossa tradução)

Em um importante sentido, Posner e Strike anteciparam muito das críticas levantadas por Pintrich, Marx e Boyle (1993). Os autores argumentaram que a teoria de Posner et al. (1982) representa um "modelo frio" de mudança conceitual que enfatiza apenas a cognição do estudante, sem considerar as maneiras pelas quais as crenças motivacionais dos estudantes e os fatores contextuais de sala de aula facilitam ou impedem a aprendizagem conceitual. Suas críticas focam em três questões. Primeiro, a metáfora da ecologia conceitual, que sugere um grupo de ideias competindo pelo mesmo nicho conceitual, é bastante limitada uma vez que ecossistemas não seguem um propósito, enquanto que aprendizes individuais e comunidades de acadêmicos têm objetivos, propósitos e intenções. Segundo, as quatro condições para a mudança 
conceitual - insatisfação, inteligibilidade, plausibilidade e fertilidade - são descritas como se o estudante operasse de uma maneira fria e racional, ignorando a influência que construtos motivacionais podem exercer sobre se tais condições podem ser satisfeitas. Finalmente, a metáfora do estudante como um cientista e a noção de sala de aula de ciências como uma comunidade de cientistas são bastante problemáticas na medida em que assumem que os objetivos e as intenções dos estudantes na escola são análogos, se são idênticos, aos objetivos e intenções dos cientistas e das comunidades científicas (Pintrich et al., 1993).

A teoria de Posner et al. (1982) não é, obviamente, a único modelo excessivamente racional de mudança conceitual. Cientistas cognitivos e psicólogos do desenvolvimento tais como Carey (1985), Chi (1992) e Vosniadou (1994), por exemplo, têm fornecido excelentes descrições de mudanças que ocorrem nas representações mentais de crianças. No entanto, a noção de resistência à mudança, tão fundamental a essa linha de pesquisa, claramente tem uma dimensão motivacional e, mesmo assim, nenhuma dessas teorias descreve explicitamente como construtos motivacionais estão implicados na criação e manutenção da relutância dos estudantes em adotar novas ideias.

Ao adotar a posição construtivista de que o processo de mudança conceitual no indivíduo é influenciado por processos pessoais, motivacionais, sociais e históricos, Pintrich et al. (1993) defenderam um "modelo quente" de mudança conceitual. Partindo da literatura sobre estudos motivacionais e sociocognitivos, os autores sugeriram um programa de pesquisa que inclua quatro construtos motivacionais: objetivos (e.g., Dweck \& Elliott, 1983), crenças de valores, (e.g., Krapp, Hidi, \& Renninger, 1992); autoeficácia (e.g., Bandura, 1986) e crenças de controle (e.g., Connell, 1985). Os objetivos são representações cognitivas dos diferentes propósitos que os estudantes podem adotar em diferentes situações. Uma distinção básica é feita entre "orientação com objetivo de domínio" e "orientação com objetivo de desempenho" (Dweck \& Leggett, 1988). Estudantes que adotam a orientação de domínio focam na aprendizagem, na compreensão e no domínio de tarefas, enquanto que aqueles que adotam uma orientação de desempenho focam na obtenção de boas notas e na superação de outros colegas. $\mathrm{O}$ contexto de sala de aula pode influenciar na adoção de uma orientação com objetivo, que por sua vez pode influenciar na natureza do processamento cognitivo do estudante. Em geral, estudantes que adotam uma orientação de domínio estão mais suscetíveis a se engajar em um processamento cognitivo mais profundo, necessários à mudança conceitual (Pintrich et al., 1993).

As crenças de valores, que por natureza são mais afetivas e relacionadas à atitude, são características pessoais que os estudantes trazem consigo ao realizar diferentes tarefas. De modo geral, os estudantes podem estar intrinsecamente interessados em um tópico, mas eles também podem valorizá-lo devido a sua importância para as opções de carreira futura. Há três crenças de valores gerais (Eccles, 1983): (1) simplesmente interesse se refere à atitude geral dos estudantes com relação ao conteúdo ou tarefa - alguns estudantes simplesmente gostam e estão interessados em Ciência; (2) valor de utilidade 
diz respeito ao julgamento instrumental dos estudantes sobre a utilidade do conteúdo ou tarefa para ajudá-los a alcançar algum objetivo específico - como conseguir um emprego ou entrar na faculdade; (3) a importância da tarefa se refere à percepção dos estudantes com relação à significância do conteúdo ou tarefa para o próprio indivíduo - as tarefas e conteúdos da Ciência podem ser percebidos como sendo mais importantes que outras para aqueles que se veem como futuros cientistas. Além das crenças de valores pessoais dos estudantes, há um número de características na sala de aula e nível de tarefa que poderia aumentar o interesse dos estudantes. Em geral, percepções de valor de uma tarefa estão relacionadas às escolhas dos estudantes em engajar-se cognitivamente na tarefa.

Outro importante aspecto da pesquisa motivacional é a autoeficácia, que é definida como as crenças de um indivíduo acerca de suas capacidades de desempenho em um domínio particular. Crenças de autoeficácia se referem ao julgamento dos estudantes sobre suas capacidades cognitivas para cumprir uma tarefa acadêmica específica. Pintrich et al. (1993) sugeriram que a noção de autoeficácia pode ser usada na pesquisa em mudança conceitual de duas maneiras distintas. Primeiro, analisando a confiança dos estudantes em suas próprias ideias e concepções; quanto mais confiança os estudantes tiverem nas suas próprias crenças, mais resistentes eles serão a novas ideias. Uma segunda maneira de incluir a autoeficácia é através da confiança que os estudantes têm na sua capacidade de mudar suas ideias. Seguindo a metáfora do cientista, a autoeficácia seria a confiança em usar métodos de pesquisa tais como teste de hipóteses para efetuar uma mudança em suas próprias concepções.

Finalmente, crenças de controle se referem a crenças dos estudantes sobre o quanto de controle eles têm sobre seu próprio comportamento ou sobre os resultados de seu desempenho. Segundo Connell (1985), há três crenças de controle gerais: (1) controle interno; (2) controle externo; (3) controle desconhecido. Em geral, estudantes que acreditam ter controle interno sobre sua própria aprendizagem têm melhor desempenho do que aqueles que acreditam em controle externo ou desconhecido. A ideia é que a percepção dos estudantes do quanto de controle eles têm sobre sua própria aprendizagem pode ter implicações para o processo de mudança conceitual. Se os estudantes não se veem como "aprendizes intencionais" (Bereiter, 1990), com algum controle sobre sua própria aprendizagem, eles podem estar menos dispostos a tentar resolver ativamente alguma discrepância entre suas concepções pré-existentes e a informação que eles recebem durante o ensino formal de Ciências. As particularidades dessa abordagem, que busca integrar motivação com uma visão mais ampla de cognição, podem ser encontradas em Pintrich (1999).

Os trabalhos de Pintrich e seus colaboradores tiveram um impacto enorme na pesquisa em mudança conceitual. Antes do artigo de 1993, as teorias tradicionais de mudança conceitual davam pouco reconhecimento a fatores afetivos, situacionais e motivacionais que influenciam, ou mesmo determinam, se uma mudança conceitual ocorre. Em geral, os modelos de mudança conceitual, propostos depois de 1993 (e.g., 
Doyle \& Sinatra, 2005; Gregoire, 2003), seguem uma "tendência aquecida" (Sinatra, 2005). Esse novo foco, inspirado por Pintrich e seus colegas, levou a criação de um novo construto teórico chamado de mudança conceitual intencional, definido como uma "iniciativa e regulação consciente e dirigida a um objetivo de processos cognitivos, metacognitivos e motivacionais para trazer uma mudança no conhecimento" (Sinatra \& Pintrich, 2005, p. 6, nossa tradução). O legado de Pintrich teve uma influência profunda não apenas na pesquisa em mudança conceitual, mas também nas visões cognitivas de aprendizagem de modo mais geral.

\section{As abordagens cognitiva e situativa}

Uma última distinção a ser feita na pesquisa em mudança conceitual é entre as abordagens cognitiva e situativa à cognição humana. Essa distinção representa a controvérsia mais recente neste campo de estudo ${ }^{2}$. Essa controvérsia, também referida como "divisão cognitivo-situativo" (Vosniadou, 2007a), tem uma longa história em debates acadêmicos, tendo sua origem nos escritos de Wilhelm Wundt, considerado por muitos como sendo "o pai da Psicologia" (Wertsch, del Rio, \& Alvarez, 1995). Nos últimos anos, no entanto, o debate entre abordagens cognitiva e situativa (sociocultural) tem sido transferido para a pesquisa em mudança conceitual (Vosniadou, 2007a).

Conforme apontado por Mason (2007), a pesquisa tradicional em mudança conceitual está situada em uma perspectiva construtivista de aprendizagem, a qual tem sido caracterizada principalmente por uma abordagem cognitiva que se concentra em analisar representações mentais individuais. Uma metáfora que sintetiza a perspectiva cognitiva de mudança conceitual é a "metáfora da aquisição" (Sfard, 1998). De acordo com essa metáfora, o conhecimento é algo que existe dentro da cabeça dos indivíduos. Uma vez adquirido, o conhecimento pode ser aplicado, compartilhado com outras pessoas e transferidos para outras situações. Tendo em vista que a aprendizagem é, com frequência, concebida como a aquisição de algo, não é surpreendente o fato de que essa metáfora "está tão fortemente enraizada em nossas mentes que nós provavelmente nunca estaríamos conscientes de sua existência se uma perspectiva alternativa não começasse a se desenvolver" (Sfard, 1998, p. 6, nossa tradução).

A metáfora da aquisição implica dois desafios à pesquisa em mudança conceitual: (1) o problema representacional, que envolve formas mais precisas de representar estruturas conceituais; (2) o problema do mecanismo de mudança, que requer o desenvolvimento de novas teorias sobre o que causa a mudança. No intuito de abraçar esses dois desafios, Carey (1986) fez um chamado de colaboração entre cientistas cognitivos e educadores em ciências. Essa colaboração, no entanto, parece envolver uma divisão de trabalho bem definida. O problema representacional deve ser resolvido por cientistas cognitivos, que têm trabalhado em novos formalismos para a representação do conhecimento científico. Já o problema do mecanismo de mudança deve ser resolvido a partir da colaboração entre os dois grupos, uma vez que são os educadores em ciências que devem testar 2 Ver número especial das revistas Education Psychologist (2007), 42(1) e Cultural Studies of Science Education (2008), 3(2). 
quaisquer ideias sobre como efetuar a reestruturação do conhecimento em sala de aula.

Na literatura em mudança conceitual, a metáfora da aquisição tem sido fortemente questionada. Um importante conjunto de críticas foi apresentado por Giyoo Hatano (1994). Ao introduzir a perspectiva japonesa à mudança conceitual, o autor argumentou que a conceitualização ocidental de mudança conceitual implica sempre uma mudança individual e cognitiva por natureza, perdendo de vista o fato de que a "mudança pode ser iniciada, facilitada ou consolidada por processos sociais" (Hatano, 1994, p. 191, nossa tradução). Além de outras características da pesquisa japonesa, o autor apresentou o coletivismo como uma perspectiva ao pensamento e à aprendizagem que diz respeito aos contextos nos quais as atividades têm lugar. De acordo com essa perspectiva, processos como a resolução de problemas, o entendimento e a aprendizagem são coletivos, apesar de parecerem individuais. Isso porque esses processos são baseados em conhecimentos e crenças compartilhados entre membros de um grupo, o que significa que a cognição individual é fortemente afetada por conhecimentos normativos e crenças do grupo, mesmo quando essa cognição é ativada pelo indivíduo em isolamento. Outro importante conjunto de críticas foi apresentado por Roger Säljö (1999). O autor criticou aquilo que ele chamou de "noções mentalistas de conceitos", segundo o qual os conceitos são construtos abstratos que intervém entre o cérebro e o comportamento. Ele argumentou que conceitos são ferramentas discursivas que fazem trabalho concreto em contextos concretos e enfatizou que seus significados não podem ser estabelecidos e entendidos fora de práticas sociais.

Esses dois conjuntos de críticas parecem ter tido um impacto profundo na pesquisa em mudança conceitual. No final dos anos 90, Vosniadou (1999) fez um novo chamado de colaboração, agora entre psicólogos do desenvolvimento e educadores em ciência. Ela reconheceu que psicólogos do desenvolvimento estão principalmente interessados em processos mentais que supostamente ocorrem dentro da cabeça dos indivíduos durante a atividade intelectual e enfatizou que as pesquisas não fornecem qualquer informação sobre variáveis externas que podem ser manipuladas para facilitar o desempenho cognitivo e a mudança conceitual. Entretanto, a autora criticou aquilo que ela chamou de "situatividade radical" por sugerir a erradicação de representações mentais. Alguns anos mais tarde, Vosniadou (2007a) aperfeiçoou sua abordagem da teoria quadro ao considerar a influência de variáveis culturais e situacionais no processo de mudança conceitual. Com base na noção de "cognição distribuída" proposta por Edwin Hutchins (1995), a autora defendeu a necessidade de adotar como unidade de análise "o indivíduo em uma interação construtiva com o mundo através de uma variedade de estruturas simbólicas mediadas, algumas internas e outras externas, em contextos socioculturais ricos" (Vosniadou, 2007a, p. 55, nossa tradução).

No outro lado da controvérsia, um conjunto complementar de pesquisadores seguiu a "virada linguística" (Lemke, 2001), montando o palco para o desenvolvimento de novas abordagens à mudança conceitual (Greeno \& Sande, 2007; Ivarsson, Schoultz, \& Säljö, 2002; Kelly \& Green, 1998; Säljö, 1999; Sfard, 2007). A metáfora que melhor 
representa a perspectiva situativa à mudança conceitual é a "metáfora da participação" (Sfard, 1998). De acordo com essa metáfora, a aprendizagem é uma questão de se tornar membro de uma comunidade. Isso implica a habilidade de se comunicar usando a linguagem dessa comunidade e de agir de acordo com suas regras específicas. Em vez de se concentrar em construtos como conceitos ou conhecimento, a metáfora da participação enfatiza noções como o "fazer", que indica ação. Nessa perspectiva, aprender é uma atividade que tem lugar entre indivíduos, as ferramentas e artefatos que eles usam e as comunidades e práticas das quais eles participam.

Mais recentemente, mudança conceitual e outros termos relacionados como "prática conceitual" (Krange, 2007) e "mudança discursiva" (Wickman \& Östman, 2002), têm se tornado tema de um renovado interesse na pesquisa sociocultural. Em um número especial da revista Cultural Studies of Science Education, Wolff-Michael Roth e seus colegas (Roth et al., 2008) desafiaram a comunidade de pesquisa em Educação em Ciências a se perguntar o que significaria considerar as noções de concepção e de mudança conceitual na perspectiva dos estudos culturais. Os autores apresentaram uma abordagem que "promete gerar explicações menos baseadas em pressuposições e mais parcimoniosas dessa questão central dentro da Educação em Ciências, do que se as concepções são supostamente estruturas habitando a mente humana" (Roth et al., 2008, p. 231, nossa tradução). Este artigo provocativo montou o palco para um acalorado debate entre os membros das duas perspectivas. A questão central desse debate, de modo mais geral, diz respeito à possibilidade de reconciliação entre as descrições cognitivas e situativas da mudança conceitual (Alexander, 2007; Greeno \& Sande, 2007; Hewson, 2008; Mercer, 2007, 2008; Roth, 2008; Smardom, 2008; Tiberghien, 2008; Treagust \& Duit, 2008a; Wells, 2008; Vosniadou, 2007a, 2008a).

Na tentativa de atender a chamada de Roth e seus colegas, Furberg e Arnseth (2009) reconsideraram a mudança conceitual a partir da análise da construção de significados dos estudantes em genética, em atividades de aprendizagem colaborativas. Situados firmemente no lado sociocultural do debate, os autores enfatizaram os aspectos discursivos e interacionais da aprendizagem dos estudantes ao substituir a expressão concepção dos estudantes por construção de significados dos estudantes. Seu estudo empírico está centrado em quatro aspectos analíticos da construção de significados: (1) o uso, pelos estudantes, de recursos na resolução de problemas; (2) intervenções do professor; (3) mudanças nas realizações em grupo; (4) o aspecto institucional do significado. De acordo com os autores, as interpretações dos estudantes de conceitos de genética são produzidas como parte de tipos específicos de práticas de construção de significados, que emergem da interação social. Assim, a mudança conceitual está relacionada não apenas a questões epistêmicas, mas também a questões interacionais e institucionais.

Mais recentemente, Pereira e Ostermann (2012) usaram as ideias de Vygotsky (1981), Bakhtin (1986) e Wertsch (1998) para formular um modelo sociocultural de mudança conceitual, baseado na noção de "distribuição conceitual”. O pressuposto básico 
desse modelo é a alegação de que tanto as concepções alternativas como as concepções científicas são mais bem entendidas como uma forma de ação mediada. A partir dessa perspectiva, as concepções em ciências são vistas como sendo distribuídas entre agentes ativos e os recursos textuais que eles empregam - especialmente recursos textuais na forma de explicação (tanto escritos quanto falados). Esse modelo difere de outras teorias de mudança conceitual ao sugerir que diferentes grupos podem gerar diferentes representações da realidade física, mesmo na comunidade científica. De acordo com essa perspectiva, as concepções são vistas como um processo ativo que frequentemente envolve disputa e contestação entre pessoas, mais do que um corpo estruturado de conhecimento que elas possuem. Nesse modelo de distribuição conceitual, a mudança conceitual é vista como "transformações da ação mediada" (Wertsch, 1998), as quais estão associadas ao surgimento de novas formas de mediação (e.g., formas explicativas) ${ }^{3}$.

\section{Considerações finais}

Neste trabalho, revisamos vários termos chave que emergem em debates acadêmicos sobre mudança conceitual. No intuito de delinear o panorama conceitual que estrutura a pesquisa internacional sobre esse tema, quatro distinções básicas foram apresentadas: (1) as abordagens clássica e reenquadrada à mudança conceitual; (2) as perspectivas da coerência e da fragmentação do conhecimento intuitivo; (3) as tendências frias e aquecidas da pesquisa em mudança conceitual; (4) as abordagens cognitiva e situativa à cognição humana. $\mathrm{O}$ ponto de partida para essa revisão é a crença de que essas quatro controvérsias formam a força motora que move a pesquisa em mudança conceitual adiante.

É importante salientar que as distinções apresentadas neste artigo não devem ser interpretadas como categorias estanques, dentro das quais diversas abordagens à mudança conceitual podem ser precisamente classificadas. Em alguns casos, essas distinções funcionam mais como tensões entre dois polos. No caso da distinção entre as abordagens cognitiva e situativa, Vosniadou argumentou que as definições envolvidas nesse debate "são muito polarizadas e não representam visões atuais [uma vez que] existem várias tentativas de aproximar as perspectivas cognitiva e situativa" (Vosniadou, 2007a, p. 56, nossa tradução). Em suma, essas quatro distinções devem ser vistas mais como ferramentas analíticas para orientar a investigação. Na situação atual em que nos encontramos, no entanto, os debates sobre mudança conceitual são, com frequência, caracterizados por perspectivas isoladas e desacordos infundados - problemas estes que resultam do fato de não sabermos exatamente onde cada um se situa em relação a pressupostos básicos. Esperamos que este artigo possa contribuir para o esclarecimento dessas questões.

3 Para mais detalhes sobre o modelo de distribuição conceitual, vide Pereira (2012, 2016). 


\section{Agradecimentos}

O autor desse trabalho agradece ao Conselho Nacional de Desenvolvimento Científico e Tecnológico (CNPq) pelo auxílio parcial à pesquisa (projeto No 441683/2014-2).

\section{Referências bibliográficas}

Alexander, P. A. (2007). Bridging cognition and socioculturalism within conceptual change research: Unnecessary foray or unachievable feat? Educational Psychologist, 42(1), 67-73.

Arabatzis, T., \& Kindi, V. (2008). The problem of conceptual change in the philosophy and history of science. In S. Vosniadou (Ed.). International handbook of research on conceptual change (pp. 345-373). New York: Routledge.

Bakhtin, M. M. (1986). Speech genres \& other late essays. Austin: University Texas Press (translated by V. W. McGee; edited by C. Emerson \& M. Holquist).

Ball, T., \& Pocock, J. G. A. (1998). Conceptual change and the Constitution. Lawrence: University Press of Kansas.

Bandura, A. (1986). Social foundations of thought and action: A social cognitive theory. Englewood Cliffs: Prentice-Hall.

Bereiter, C. (1990). Aspects of an educational learning theory. Review of Educational Research, 60(4), 603-624.

Caravita, S. (2001). Commentary: A re-framed conceptual change theory? Learning and Instruction, 11, 421-429.

Caravita, S., \& Halldén, O. (1994). Re-framing the problem of conceptual change. Learning and Instruction, 4, 89-112.

Carey, S. (1985). Conceptual change in childhood. Cambridge: MIT Press.

Carey, S. (1986). Cognitive science and science education. American Psychologist, 41(10), $1123-1130$.

Chi, M, T. H. (1992). Conceptual change within and across ontological categories: Examples from learning and discovery in science. In R. Giere (Ed.). Cognitive models of science: Minnesota studies in the philosophy of science (pp. 129-160). Minnesota: University of Minnesota Press.

Chi, M. T. H., \& Roscoe, R. D. (2002). The processes and challenges of conceptual change. In M. Limón \& L. Mason (Eds.). Reconsidering conceptual change: Issues in theory and practice (pp. 3-27). Dordrecht: Kluwer Academic Publishers.

Chi, M. T. H., Slotta, J. D., \& Leeuw, N. (1994). From things to processes: A theory of conceptual change for learning science concepts. Learning and Instruction, 4, 27-43. 
Clark, D. B. (2003, March). Analyzing student knowledge integration: Theories or pieces? Paper presented at the annual meeting of the National Association of Research in Science Teaching, Philadelphia, PA.

Clement, J. (1982). Students' preconceptions in introductory mechanics. American Journal of Physics, 50(1), 66-70.

Cobern, W. W. (1996). Worldview theory and conceptual change in science education. Science Education, 80, 579-610.

Connell, J. P. (1985). A new multidimensional measure of children's perceptions of control. Child Development, 56, 1018-1041.

diSessa, A. A. (1988). Knowledge in pieces. In G. Foreman \& P. Pufall (Eds.). Constructivism in the computer age (pp. 49-70). Mahwah: Lawrence Erlbaum Associates.

diSessa, A. A. (1993). Toward an epistemology of physics. Cognition and Instruction, $10(2 / 3), 105-225$.

diSessa, A. A. (2002). Why "conceptual ecology" is a good idea. In M. Limón \& L. Mason (Eds.).Reconsidering conceptual change: Issues in theory and practice (pp. 29-60). Dortrecht: Kluwer.

diSessa, A. A. (2006). A history of conceptual change research: Threads and fault lines. In K. Sawyer (Ed.). Cambridge handbook of the learning sciences (pp. 265-281). Cambridge: Cambridge University Press.

diSessa, A. A., \& Sherin, B. (1998). What changes in conceptual change? International Journal of Science Education, 20(1), 1155-1191.

diSessa, A. A., Gillespie, N. M., \& Esterly, J. B. (2004). Coherence versus fragmentation in the development of the concept of force. Cognitive Science, 28, 843-900.

Dole, J. A., \& Sinatra, G. M. (1998). Reconceptualizing change in the cognitive construction of knowledge. Educational Psychologist, 33(2/3), 109-128.

Driver, R. (1989). Student's Conceptions and the Learning of Science. International Journal of Science Education, 11(5), 481-490.

Duit, R., \& Treagust, D. F. (2003). Conceptual change: A powerful framework for improving science teaching and learning. International Journal of Science Education, 25(6), 671-688.

Dweck, C. S., \& Elliott, E. S. (1983). Achievement motivation. In E. M. Heatherington (Ed.). Handbook of child psychology, Vol. 4: Socialization, personality, and social development (pp. 643-691). New York: Wiley.

Dweck, C. S., \& Leggett, E. L. (1988). A social-cognitive approach to motivation and personality. Psychological Review, 95(2), 256-273. 
Eccles, J. (1983). Expectancies, values and academic behaviors. In J. T. Spence (Ed.), Achievement and achievement motives (pp. 75-146). San Francisco: Freeman.

Furberg, A., \& Arnseth, H. C. (2009). Reconsidering conceptual change from a sociocultural perspective: analyzing students' meaning making in genetics in collaborative learning activities. Cultural Studies of Science Education, 4, 157-191.

Greeno, J. G., \& Sande, C. (2007). Perspectival understanding of conceptions and conceptual growth in interaction. Educational Psychologist, 42(1), 9-23.

Gregoire, M. (2003). Is it a challenge or a threat? A dual-process model of teachers' cognition and appraisal process during conceptual change. Educational Psychology Review, 15, 117-155.

Guzzetti, B., \& Hynd, C. (1998). Perspectives on conceptual change: multiple ways to understand knowing and learning in a complex world. New Jersey: Lawrence Erlbaum Associates.

Hatano, G. (1994). Introduction: Conceptual change - Japanese perspectives. Human Development, 37, 189-197.

Hewson, P. W. (1981). A conceptual change approach to learning science. European Journal of Science Education, 3(4), 383-396.

Hewson, P. W. (1992, June). Conceptual change in science teaching and teacher education. Paper presented at the Meeting on Research and Curriculum Development in Science Teaching, Madrid, Spain.

Hewson, P. W. (2008). Conceptions over time: Are language and here-and-now up to the task? Cultural Studies of Science Education, 3, 263-276.

Hunt, E., \& Minstrell, J. (1994). A cognitive approach to the teaching of physics. In McGilly (Ed.). Classroom lessons: Integrating cognitive theory and classroom practice. Cambridge (pp. 51-74). Cambridge: MIT Press.

Hutchins, E. (1995). Cognition in the wild. Cambridge: MIT Press.

Ivarsson, J., Schoultz, J., \& Säljö, R. (2002). Map reading versus mind reading: Revisiting children's understanding of the shape of the earth. In M. Limón, \& L. Mason (Eds.). Reconsidering conceptual change: Issues in theory and practice (pp. 77-99). Dordrecht: Kluwer Academic Publishers.

Kaufman, D. R., Keselman, A., \& Patel, V. L. (2008). Changing Conceptions in Medicine and Health. In S. Vosniadou (Ed.). International handbook of research on conceptual change (pp. 295-327). New York: Routledge.

Kelly, G. J., \& Green, J. (1998). The social nature of learning: Toward a sociocultural perspective on conceptual change and knowledge construction. In B. Guzzetti \& C. Hynd (Eds.). Perspectives on conceptual change: Multiple ways to understand knowing and learning in a complex world (pp. 145-181). Mahwah: Lawrence Erlbaum Associates, Inc. 
Krange, I. (2007). Students' conceptual practices in science education: Productive disciplinary interactions in a participation trajectory. Cultural Studies of Science Education, 2, 171-203.

Krapp, A., Hidi, S., \& Renninger, K. A. (1992). Interest, learning, and development. In K. A. Renninger, S. Hidi, \& A. Krapp (Eds.).The role of interest in learning and development (pp. 3-25). Hillsdale: Erlbaum.

Kuhn, T. S. (1970). The structure of scientific revolutions. Chicago: University of Chicago Press (first published in 1962).

Lakatos, I. (1970). Falsification and the methodology of scientific research programmes. In I. Lakatos \& A. Musgrave (Eds.), Criticism and the growth of knowledge (pp. 170-196). Cambridge: Cambridge University Press.

Lemke, J. L. (2001). Articulating communities: Sociocultural perspectives on science education. Journal of Research in Science Teaching, 38(3), 296-316.

Limón, M. (2001). On the cognitive conflict as an instructional strategy for conceptual change: a critical appraisal. Learning and Instruction, 11, 357-380.

Limón, M. (2002). Conceptual Change in History. In M. Limón \& L. Mason (Eds.). Reconsidering conceptual change: Issues in theory and practice (pp. 259-289). Dordrecht: Kluwer Academic Publishers.

Limón, M., \& Mason, L. (2002). Reconsidering conceptual change: Issues in theory and practice. Dordrecht: Kluwer Academic Publishers.

Linder, C. J. (1993). A challenge to conceptual change. Science Education, 77, 293-300.

Mason, L. (2007). I ntroduction: bridging the cognitive and sociocultural approaches in research on conceptual change: Is it feasible? Educational Psychologist, 42(1), 1-7.

McCloskey, M. (1983). Naïve theories of motion. In D. Gentner \& A. L. Stevens (Eds.). Mental Models (pp. 299-324). Mahwah: Lawrence Erlbaum Associates.

Mercer, N. (2007). Commentary on the reconciliation of cognitive and sociocultural accounts of conceptual change. Educational Psychologist, 42(1) 75-78.

Mercer, N. (2008). Changing our minds: A commentary on 'Conceptual change: a discussion of theoretical, methodological and practical challenges for science education'. Cultural Studies of Science Education, 3, 351-362.

Minstrell, J. (1982). Explaining the "at rest condition" of an object. The Physics Teacher, 20(1), 10-14.

Mortimer, E. F. (1995). Conceptual change or conceptual profile change? Science \& Education, 3, 267-285. 
Niedderer, H., Goldberg, F., \& Duit, R. (1991). Towards learning process studies: A review of the workshop on research in physics learning. In R. Duit, F. Goldberg, \& H. Niedderer (Eds.). Research in physics learning: Theoretical issues and empirical studies (pp. 10-28). Kiel: Schmidt \& Klannig.

Özdemir, G., \& Clark, D. B. An overview of conceptual change theories. Eurasia Journal of Mathematics, Science \& Technology Education, 3(4), 351-361.

Pereira, A.P. (2012). Distribuição conceitual no ensino de física quântica: uma aproximação sociocultural às teorias de mudança conceitual. Tese de Doutorado, Universidade Federal do Rio Grande do Sul, Porto Alegre.

Pereira, A. P. (2016). Bases teóricas para um modelo de "distribuição conceitual" na Educação em Ciências. Revista Brasileira de Pesquisa em Educação em Ciências, 16(3), 671-692.

Pereira, A. P., \& Ostermann, F. (2012, September). Conceptual distribution and the Problem of conceptual change. Paper presented at the 8th International Conference on Conceptual Change, Trier, Germany.

Pintrich, P. R. (1999). Motivational beliefs as resources for and constraints on conceptual change. In W. Schnotz, S. Vosniadou, \& M. Carretero (Eds.). New perspectives on conceptual change (pp. 33-50). Amsterdam: Pergamon.

Pintrich, P. R., Marx, R. W., \& Boyle, R. A. (1993). Beyond cold conceptual change: The role of motivational beliefs and classroom contextual factors in the process of conceptual change. Review of Educational Research, 63, 167-199.

Posner, G. J., Strike, K. A., Hewson, P. W., \& Gertzog, W. A. (1982). Accommodation of a scientific conception: Toward a theory of conceptual change. Science Education, 66, 211-227.

Pozo, J., Gómez, M., \& Sanz, A. (1999). When change does not mean replacement: Different representations for different contexts. In W. Schnotz, S. Vosniadou, \& M. Carretero (Eds.). New perspectives on conceptual change (pp. 161-174). Amsterdam: Pergamon.

Roth, W.-M. (2008). A question of competing paradigms? Cultural Studies of Science Education, 3, 373-385.

Roth, W.-M., Lee, Y. J., \& Hwang, S. (2008). Culturing Conceptions: From First Principles. Cultural Studies of Science Education, 3, 231-261.

Säljö, R. (1999). Concepts, cognition and discourse: From mental structure to discursive tools. In W. Schnotz, S. Vosniadou, \& M. Carretero (Eds.). New perspectives on conceptual change (pp. 81-90). Amsterdam: Pergamon.

Schnotz, W., Vosniadou, S., \& Carretero. M. (1999). New Perspectives on Conceptual Change. Oxford: Elsevier. 
Sfard, A. (2007). Reconceptualizing conceptual change. In S. Vosniadou, A. Baltas, \& X. Vamvakoussi (Eds.). Re-framing the conceptual change approach in learning and instruction (pp. 329-334). Oxford: Elsevier.

Sfard, A. (1998). On two metaphors for learning and the danger of choosing just one. Educational Researcher, 27(2), 4-13.

Smardom, R. (2008). Some sociological ideas for conceptual change research. Cultural Studies of Science Education, 3, 363-371.

Sinatra, G. M. (2005). The "warming trend" in conceptual change research: The legacy of Paul R. Pintrich. Educational Psychologist, 40(2), 107-115.

Sinatra, G. M. \& Pintrich, P. R. (2003). Intentional conceptual change. New Jersey: Lawrence Erlbaum Associates.

Solomon, J. (1983). Learning about energy: how pupils think in two domains. European Journal of Science Education, 5(1), 49-59.

Spada, H. (1994). Conceptual change or multiple representations? Learning and Instruction, 4, 113-116.

Strike, K. A. \& Posner, G. J. (1992). A revisionist theory of conceptual change. In R. Duschl \& R. Hamilton (Eds.). Philosophy of science, cognitive psychology, and educational theory and practice (pp. 147-176). Albany: Suny Press.

Thagard, P. (1992). Conceptual revolutions. Princeton: Princeton University Press.

Tiberghien, A. (2008). Students' conception: culturing conceptions. Cultural Studies of Science Education, 3, 283-295.

Toulmin, S. (1972). Human understanding. Princeton: Princeton University Press.

Treagust, D. F., \& Duit, R. (2008a). Compatibility between cultural studies and conceptual change in science education: there is more to acknowledge than to fight straw men! Cultural Studies of Science Education, 3, 387-395.

Treagust, D. F., \& Duit, R. (2008b). Conceptual change: a discussion of theoretical, methodological and practical challenges for science education. Cultural Studies of Science Education, 3, 297-328.

Treagust, D. F., \& Duit, R. (2009). Multiple Perspectives of Conceptual Change in Science and the Challenges Ahead. Journal of Science and Mathematics Education in Southeast Asia, 32(2), 89-104.

Tyson, L. M., Venville, G. J., Harrison, A. G., \& Treagust, D. F. (1997). A Multidimensional framework for interpreting conceptual change events in the classroom. Science Education, 81, 387-404.

Viennot, L. (1979). Spontaneous reasoning in elementary dynamics. European Journal of Science Education, 1(2), 205-21. 
Vosniadou, S. (1994). Capturing and modeling the process of conceptual change. Learning and Instruction, 4, 45-69.

Vosniadou, S. (1999). Conceptual change research: State of the art and future directions. In W. Schnotz, S. Vosniadou, \& M. Carretero (Eds.). New Perspectives on Conceptual Change (3-13). Oxford: Elsevier.

Vosniadou, S. (2002). On the nature of naïve physics. In M. Limón \& L. Mason (Eds.). Reconsidering conceptual change: Issues in theory and practice (pp. 61-76). Dordrecht: Kluwer Academic Publishers.

Vosniadou, S. (2007a). The cognitive-situative divide and the problem of conceptual change. Educational Psychologist, 42(1), 55-66.

Vosniadou, S. (2007b). The conceptual change approach and its re-framing. In S. Vosniadou, A. Baltas, \& X. Vamvakoussi (Eds.). Reframing the conceptual change approach in learning and instruction (pp 1-15). Oxford: Elsevier.

Vosniadou, S. (2008a). Bridging culture with cognition: a commentary on "culturing conceptions: from first principles. Cultural Studies of Science Education, 3, 277-282.

Vosniadou, S. (2008b). Conceptual change research: An introduction. In S. Vosniadou (Ed.). International handbook of research on conceptual change (pp. xiii-xxviii). New York: Routledge.

Vosniadou, S. (2008c). International handbook of research on conceptual change. New York: Routledge.

Vosniadou, S., \& Brewer, W. F. (1992). Mental models of the earth: A study of conceptual change in childhood. Cognitive Psychology, 24, 535-585.

Vosniadou, S., \& Verschaffel, L. (2004). Editorial: Extending the conceptual change approach to mathematics learning and teaching. Learning and Instruction, 14, 445-451.

Vosniadou, S., Baltas, A., \& Vamvakoussi, X. (2007). Re-framing the conceptual change approach in learning and instruction. Oxford: Elsevier.

Vygotsky, L. S. (1981). The instrumental method in psychology. In J. V. Wertsch (Ed.). The concept of activity in Soviet psychology (pp. 134-143). Armonk: Sharpe.

Wells, G. (2008). Learning to use scientific concepts. Cultural Studies of Science Education, 3, 329-350.

Wertsch, J. V. (1998). Mind as action. New York: Oxford University Press.

Wertsch, J. V., del Rio, P., \& Alvarez, A. (1995). Sociocultural studies: History, action, and mediation. In J. V. Wertsch, P. del Rio, \& A. Alvarez (Eds.). Sociocultural studies of mind (pp. 1-34). New York: Cambridge University Press.

Wertsch, J. V., \& Roediger, H. L. (2008) Collective memory: Conceptual foundations and theoretical approaches. Memory, 16(3), 318-326. 
White, R. T. (1994). Conceptual and conceptional change. Learning and Instruction, 4, 117-121.

Wickman, P.-O., \& Östman, L. (2002). Learning as discourse change: A sociocultural mechanism, Science Education, 86, 601-623.

Wiser, M., \& Carey, S. (1983). When heat and temperature were one. In D. Gentner \& A. Stevens (Eds.). Mental models (pp. 267-297). Mahwah: Lawrence Erlbaum Associates.

\author{
Alexsandro Pereira de Pereira \\ (1) http://orcid.org/0000-0001-8689-3054 \\ Universidade Federal do Rio Grande do Sul \\ Instituto de Física \\ Departamento de Física \\ Porto Alegre, Brasil \\ alexsandro.pereira@ufrgs.br
}

